\title{
Impact of community participation on treatment outcomes and compliance of DOTS patients in Iraq
}

A.D. Niazi ${ }^{1}$ and A.M. Al-Delaimi ${ }^{2}$

$$
\begin{aligned}
& \text { أثرّ مساهمة الجمتمع في حصائل المعالجة وامتثال المرضى للمعابلة القصيرة الأمد تحت الإثراف المباشر } \\
& \text { في العراق } \\
& \text { أبجد داود نيازي، عايد موات حان الدليمي }
\end{aligned}
$$

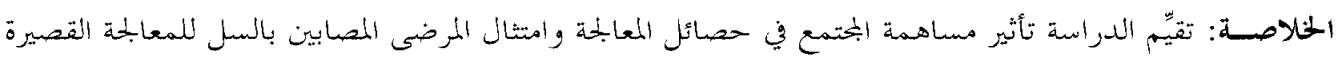

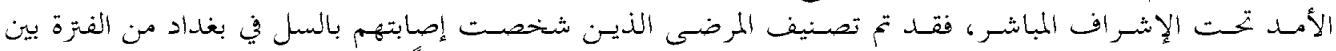

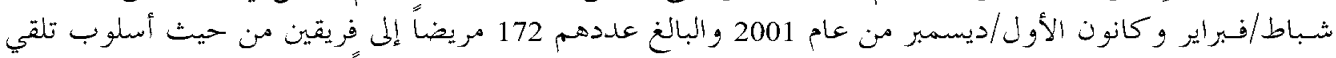

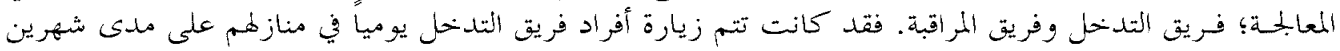

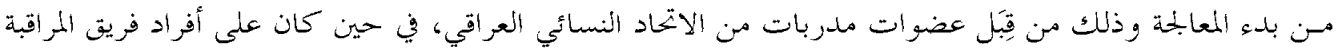

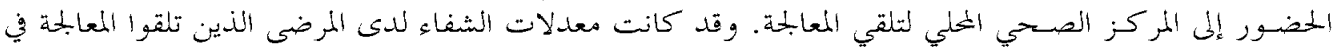

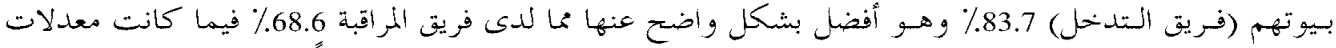

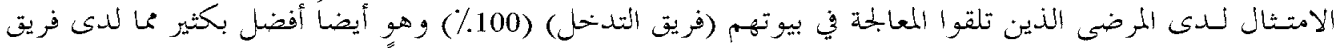

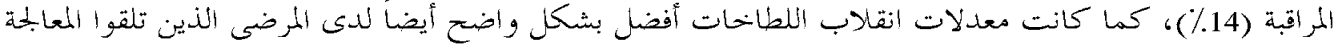

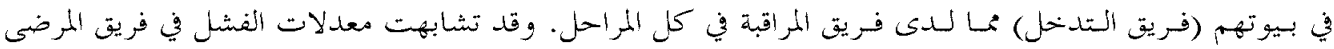

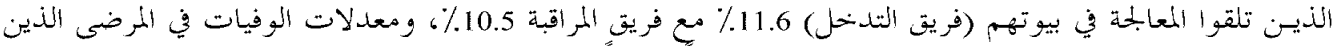

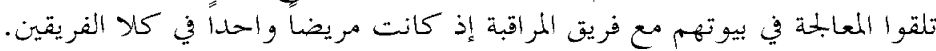

ABSTRACT We assessed the effect of community participation on treatment outcomes for tuberculosis patients undergoing directly-observed therapy, short course (DOTS). From February to December 2001 172 newly diagnosed patients in Baghdad were allocated into 2 treatment groups. The intervention group were visited daily at home for the 2-month initial phase by trained members of the Iraqi Women's Federation while the control group attended the local health centre for treatment. Cure rates for patients treated at home were significantly better than controls $(83.7 \%$ versus $68.6 \%)$, so too was compliance $(100.0 \%$ versus $14.0 \%)$. Smear conversion rates were significantly better in intervention cases compared with controls at all stages. Default rates were similar in both groups (11.6\% versus $10.5 \%)$, as was mortality (1 patient each).

Impact de la participation communautaire sur l'issue du traitement et l'observance des patients sous traitement DOTS en Iraq

RESUME L'étude a évalué l'effet de la participation communautaire sur l'issue du traitement pour les patients tuberculeux sous traitement DOTS. Entre février et décembre 2001, 172 cas de tuberculose récemment diagnostiqués à Bagdad ont été répartis dans deux groupes de traitement. Le groupe de l'intervention a reçu la visite quotidienne à domicile de membres qualifiés de la Fédération des Femmes iraquiennes pendant la phase initiale de 2 mois tandis que le groupe témoin se rendait au centre de santé local pour le traitement. Les taux de guérison pour les patients traités à domicile étaient nettement plus élevés que ceux des témoins $(83,7 \%$ contre $68,6 \%)$, tout comme l'observance $(100,0 \%$ contre $14,0 \%)$. Les taux de conversion des frottis dans le groupe de l'intervention étaient nettement plus élevés que ceux du groupe témoin à tous les stades. Les taux d'abandon du traitement étaient identiques pour les deux groupes (11,6\% contre 10,5\%), tout comme la mortalité (1 patient dans chaque groupe).

${ }^{1}$ Department of Community Medicine, Iraqi College of Medicine, Kadmiya, Baghdad, Iraq. ${ }^{2}$ Directorate General of Preventive Medicine, Ministry of Health, Baghdad, Iraq.

المجلة الصحية لشرق المتوسط، منظمة الصحة العالمية، المجلد التاسع، العدد ع، ب. ب. 


\section{Introduction}

The treatment of tuberculosis (TB) is a time-consuming and expensive process. Directly observed therapy, short course (DOTS) is a critical control strategy in TB treatment for reducing the emergence of drug resistance and for avoiding the transmission of resistant organisms [1]. Poor patient compliance is a major factor contributing to the development of resistant infections as well as relapse [2], and the high rate of defaulting is one reason why the WHO-recommended DOTS strategy is perceived to be expensive [3].

There is evidence that compliance in tuberculosis (TB) programmes can be improved through interventions. The involvement of nongovernmental organizations (NGOs) in supporting patients has been studied in a number of countries. In Nepal, the role of home visiting and supervision of DOTS therapy by an NGO was studied in a cohort of 205 smear-positive patients [4]. Almost one-third of new smear-positive cases were visited and $14 \%$ of patients required home visits to ensure treatment completion. A study in Vaud county in Switzerland showed that the success rate (cure or adequately completed treatment) was $70 \%$, the defaulter rate was $16 \%$ and death rate $14 \%$ when patients were treated by independent practitioners [5]. In Jordan, the Anti-TB Association has made a major contribution to the National Tuberculosis Control Programme. In Egypt, a growing number of NGOs collaborate with the national programme in DOTS implementation, health education, contact tracing, and defaulter retrieving, also in TB advocacy and financial support to TB patients [6].

TB is a major public health problem in Iraq, and there has been a $50 \%$ increase in the notification rate during the last 4 years.
The present notification rate of TB in Iraq is high at 135 per 100000 population. The defaulter rate in the Saddam city pilot project is 7\% (Al-Delami AM, unpublished report, 1999). Ways of improving the treatment outcomes of the DOTS strategy are urgently needed to decrease the non-compliance and defaulter rates. This in turn will help reduce transmission of the disease by killing the TB bacilli at source as early as possible.

The aim of this study was to assess the effect of home visits and support by a local NGO, the Iraqi Women's Federation (IWF), on outcomes of DOTS therapy: sputum smear conversion, cure and default rates, and patient compliance with treatment.

\section{Methods}

This study was conducted from February to December 2001 in Saddam city in Baghdad, which has a population of about 2 million.

\section{Study design}

The design was a community intervention study with patients allocated to control or intervention groups. Patients were included in the study if they were diagnosed by the TB Institute, Baghdad, using the WHO criteria for diagnosis of 3 consecutive positive sputum smears by direct Ziehl-Neelsen stain. A total of 172 newly diagnosed TB cases were enrolled. The TB coordinator allocated them alternately to the intervention or control group according to their order of attendance.

Both groups of patients were newly diagnosed TB cases from the same city treated by the standard 6-month DOTS therapy: a 2-month supervised initial phase of treatment (rifampicin, isoniazide, pyrazinamide, ethambutol or streptomycin) and a 4-

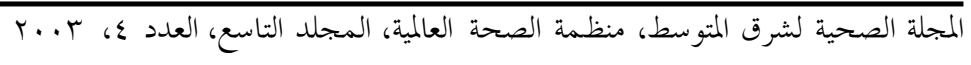


month unsupervised continuation phase (rifampicin and isoniazide).

The intervention group received daily visits at their home by members of the IWF for the 2-month initial phase of treatment and were directly supervised taking their drugs. For the 4-month continuation phase, patients were expected to attend the nearest primary health care centre daily to receive their medication without supervision.

The control group had the conventional method of delivering anti-TB drugs without any supervision by the IWF. Patients were expected to attend the primary health care centre daily for 6 months; they were directly observed taking their medication for the 2-month initial phase of treatment and after that received their medication without supervision.

\section{Training of IWF}

Twenty members of the IWF were nominated and selected from the local organization of the IWF in Saddam city and trained for 2 days on the problem of TB in general and on the treatment of the disease and close supervision of DOTS in particular. Training included how to approach patients daily and administer the anti-TB drugs during the 2 months initial DOTS phase. They were taught about adherence to the schedule of visits and treatment and the provision of direct daily hand-to-mouth therapy for patients assigned to them. After that, they were responsible for monthly follow-up of patients. IWF members were taught to give health education to the patient and his/her family about TB and its transmission. The programme was strictly observed and adherence was checked by the TB coordinator. IWF members were also responsible for data collection and completion of questionnaires about sociodemographic characteristics, while treatment outcome and compliance were monitored by the TB coordinator.

\section{Data collection}

Patients from the 2 groups were followed up to measure the following:

- Sputum smear conversion rate at various stages of treatment: number of smear-positive patients who changed to smear-negative divided by the total number of smear-positives. Sputum samples were analysed at the end of 1 , 2, 3 and 5 months after the start of treatment

- Cure rate: percentage of patients who were sputum smear-negative in the last month of treatment and on at least one previous occasion.

- Treatment failure rate: percentage of patients who were sputum smear-positive at 5 months or later during treatment.

- Mortality rate.

- Defaulter rate: percentage of patients who did not collect their medication for 2 consecutive months or more.

As a measure of non-compliance with the schedule of treatment the number of missed days (i.e. number of missed doses, as drugs were dispensed daily) for each patient was used.

\section{Analysis}

Statistical analysis was made using SPSS, version 10.0.

\section{Results}

There were no significant differences between the control and intervention groups in most of the sociodemographic characteristics (Table 1): age, sex, type of family and occupation. However, significantly more of the intervention group subjects owned their houses than did the controls, and the crowding index (number of house-

المجلة الصحية لشرق المتوسط، منظمة الصحة العالمية، المجلد التاسع، العدد ع، بr..r 
hold members divided by the number of rooms in the household) was significantly higher for controls than the intervention group $(P<0.0001)$.

Of the 172 patients, 103 (59.9\%) had index cases, mostly household members (37.2\%).

After the first month of treatment, $86.1 \%$ of intervention and $64.0 \%$ of control patients had converted to sputum-negative $(P=0.0015)$ (Table 2$)$. Sputum smear conversion rates increased steadily over the period of treatment in both groups but were significantly higher in the intervention group compared with the control group at all stages: after 1, 2, 3 and 5 months of treatment. At the end of 5 months, $97.7 \%$ of intervention patients were smear-negative compared with only $80.2 \%$ of controls $(P<0.001)$. There was a significant trend in the smear conversion rate over time in the intervention compared with the control group ( $\chi^{2}$ for trend $=35.17, P<0.001$ ).

Comparing the groups at the end of treatment showed the TB cure rate was significantly higher for the intervention group (83.7\%) compared with the control group (68.6\%, $P=0.031$ ). However, there was no significant difference in the default rate between the groups: $11.6 \%$ for intervention (10/86) and $10.5 \%$ for control pa-

\begin{tabular}{|c|c|c|c|c|c|c|}
\hline Variable & $\begin{array}{r}\text { Interv } \\
\text { patients }\end{array}$ & $\begin{array}{l}\text { ntion } \\
(n=86)\end{array}$ & $\begin{array}{r}\text { Cor } \\
\text { patients }\end{array}$ & $\begin{array}{l}\text { trol } \\
(n=86)\end{array}$ & Significe & $n c e^{a, b}$ \\
\hline & No. & $\%$ & No. & $\%$ & & \\
\hline Family type & & & & & & \\
\hline Extended & 41 & 47.7 & 47 & 54.7 & $\chi^{2}=0.58$ & $P=0.446$ \\
\hline Nuclear & 45 & 52.3 & 39 & 45.4 & & \\
\hline Sex & & & & & & \\
\hline Male & 55 & 64.0 & 56 & 65.1 & $\chi^{2}=0.03$ & $P=0.87$ \\
\hline Female & 31 & 36.1 & 30 & 34.9 & & \\
\hline House & & & & & & \\
\hline Rented & 18 & 20.9 & 37 & 43.0 & $\chi^{2}=8.66$ & $P=0.003$ \\
\hline Owned & 68 & 79.1 & 49 & 57.0 & & \\
\hline Occupation & & & & & & \\
\hline Unskilled worker & 36 & 41.9 & 28 & 32.6 & $\chi^{2}=2.31$ & $P=0.315$ \\
\hline Other occupation & 23 & 26.7 & 22 & 25.6 & & \\
\hline Unemployed & 27 & 31.4 & 36 & 41.9 & & \\
\hline Age (mean years $\pm \mathrm{s}$ ) & 33.6 & \pm 14.5 & 33.2 & \pm 15.3 & $t=0.169$ & $P=0.866$ \\
\hline $\begin{array}{l}\text { Household crowding } \\
\text { index (mean no. } \pm \mathrm{s} \text { ) }\end{array}$ & 3.73 & \pm 0.02 & 4.36 & \pm 0.02 & $t=-211.79$ & $P<0.0001$ \\
\hline
\end{tabular}

المجلة الصحية لشرق المتوسط، منظمة الصحة العالمية، المجلد التاسع، العدد ع، بr.بr 
Table 2 Sputum smear conversion rates at different stages of treatment, treatment outcome and non-compliance in intervention and control group patients

\begin{tabular}{|c|c|c|c|c|c|c|}
\hline \multirow[t]{2}{*}{$\begin{array}{l}\text { Conversion rates/ } \\
\text { outcome }\end{array}$} & \multicolumn{2}{|c|}{$\begin{array}{c}\text { Intervention } \\
\text { patients }(n=86)\end{array}$} & \multicolumn{2}{|c|}{$\begin{array}{c}\text { Control } \\
\text { patients }(n=86)\end{array}$} & \multicolumn{2}{|c|}{ Significance $^{a, b}$} \\
\hline & No. & $\%$ & No. & $\%$ & & \\
\hline \multicolumn{7}{|l|}{$\begin{array}{l}\text { Conversion to smear } \\
\text { negative after: }\end{array}$} \\
\hline Month 1 & 74 & 86.1 & 55 & 64.0 & $\chi^{2}=10.05$ & $P=0.0015$ \\
\hline Month 2 & 78 & 90.7 & 67 & 77.9 & $\chi^{2}=4.39$ & $P=0.036$ \\
\hline Month 3 & 81 & 94.2 & 68 & 79.1 & $\chi^{2}=7.23$ & $P=0.0071$ \\
\hline \multirow[t]{2}{*}{ Month 5} & 84 & 97.7 & 69 & 80.2 & $\chi^{2}=11.6$ & $P=0.0006$ \\
\hline & \multicolumn{6}{|c|}{$\chi^{2}=35.17, P<0.001$} \\
\hline \multicolumn{7}{|l|}{ Treatment outcome } \\
\hline Cured & 72 & 83.7 & 59 & 68.6 & $\chi^{2}=5.41$ & $P=0.02$ \\
\hline Failed & 3 & 3.5 & 17 & 20.0 & $\chi^{2}=11.09$ & $P=0.0009$ \\
\hline Defaulted & 10 & 11.6 & 9 & 10.5 & $\chi^{2}=0.00$ & NS \\
\hline Died & 1 & 1.2 & 1 & 1.2 & $F=1.00$ & NS \\
\hline $\begin{array}{l}\text { Non-compliant with } \\
\text { treatment }\end{array}$ & 0 & 0.0 & 74 & 86.1 & & \\
\hline
\end{tabular}

${ }^{\mathrm{a}} \chi^{2}=$ Yates corrected $\chi^{2}$ test.

${ }^{b} \mathrm{~F}=$ Fisher exact test.

$\mathrm{n}=$ number of new smear-positive patients at start of treatment.

NS = not significant.

tients (9/86) (Table 2). The mortality rate (1 patient) was the same in both groups.

The proportion of patients who were non-compliant with treatment was zero in the intervention group (defaulters were not considered to be non-compliant) (Table 2). The overall non-compliance rate in the control group was $86.1 \%$ (74 patients out of 86).

The mean duration of non-compliance and mean number of doses in the control group were compared among the defaulters, cured and failed patients at the end of treatment (Table 3). The mean \pm SD duration of non-compliance was $5.87 \pm 4.13$ days overall. Failed cases recorded a significantly higher level of non-compliance in terms of mean number of days when doses were missed (8.53 versus 5.30 for defaulters and 5.20 for cured patients respective- ly) $(P=0.011)$. There was no significant difference between the mean durations of non-compliance in the control group during the different months of treatment (Table 3).

When analysing the effect of missed days (doses) on outcome of treatment, there was a significant relationship between the number of missed does and patient outcome $(P=0.004)$ (Table 4). Applying logistic regression, it was found that there was a significant inverse relationship of cure with number of doses missed $(P=$ 0.03 ) and the cut-off point was 8 days/doses and more $\left(\chi^{2}=3.99, P=0.04\right)$.

\section{Discussion}

The study was designed to compare the effect of home supervision by members of an NGO with the conventional method of clin-

المجلة الصحية لشرق المتوسط، منظمة الصحة العالمية، المجلد التاسع، العدد ع، ب...T 


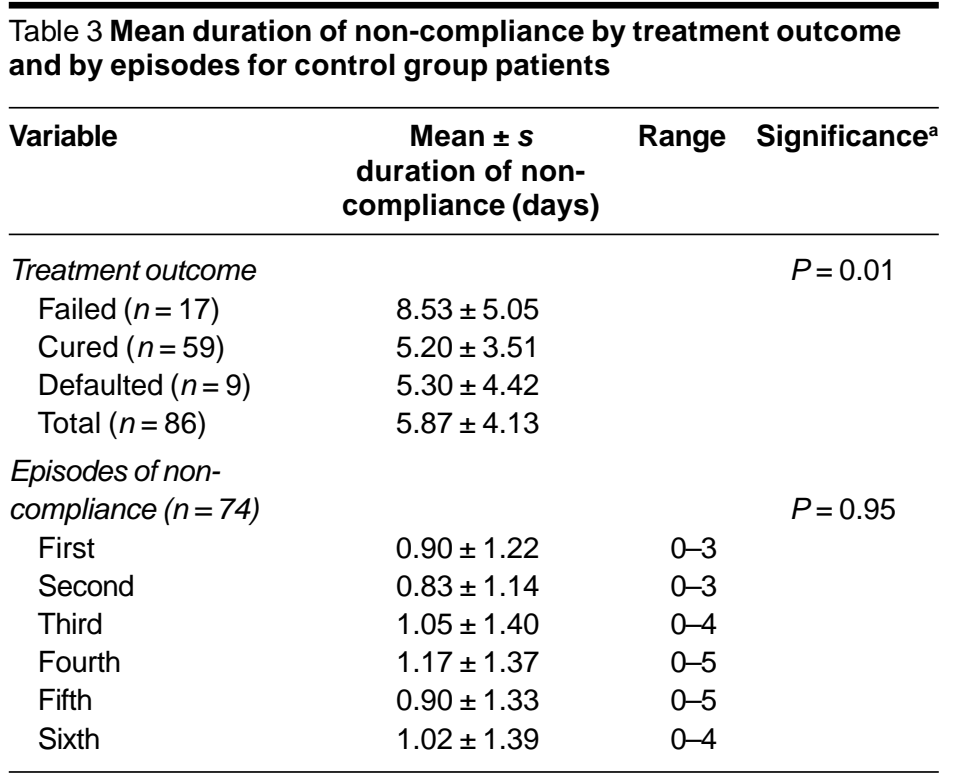

aKruskal-Wallis test

$s$ = standard deviation.

$\mathrm{n}=$ number of control group patients.

ic attendance for DOTS treatment. As there were no significant differences in sociodemographic characteristics between the control and intervention groups and because patients were randomly assigned to the 2 groups and came from the same district, any differences between the groups are likely to come from the intervention alone. We found a major deficiency in contact tracing as nearly $60 \%$ of our cases had index and could have been prevented by proper chemoprophylaxis.

It was shown clearly that there was a significantly higher risk for TB patients at all stages of treatment of remaining sputum-positive by the conventional method of

\begin{tabular}{|c|c|c|c|c|}
\hline \multirow{2}{*}{$\begin{array}{l}\text { No. of missed } \\
\text { doses }^{a}\end{array}$} & \multicolumn{3}{|c|}{ Treatment outcome } & \multirow[t]{2}{*}{ Significance } \\
\hline & $\begin{array}{c}\text { Cured } \\
(n=59) \\
\text { No. }\end{array}$ & $\begin{array}{c}\text { Failed }^{\mathrm{b}} \\
(n=17) \\
\text { No. }\end{array}$ & $\begin{array}{c}\text { Total } \\
(n=76) \\
\text { No. }\end{array}$ & \\
\hline $0-5$ & 29 & 5 & 34 & $\chi^{2}=10.65, P=0.004$ \\
\hline $6-10$ & 25 & 5 & 30 & \\
\hline $11-15$ & 5 & 7 & 12 & \\
\hline
\end{tabular}

${ }^{a}$ Number of missed doses of the dead person was 4 .

${ }^{b}$ Excluding treatment defaulters and deaths.

$\mathrm{n}=$ number of control group patients.

المجلة الصحية لشرق المتوسط، منظمة الصحة العالمية، المجلد التاسع، العدد ع، ب... 
DOTS treatment compared with being supervised on a daily basis at home by trained volunteers. Furthermore, the magnitude of the risk increased with time of follow-up as sputum conversion rates significantly increased with increasing periods of treatment. The defaulter rate (around 10\%) and the mortality rate (around 1\%) were not significantly different between the groups. These figures agree with other studies from the Far East $[7,8]$.

The WHO global target for TB treatment is an $85 \%$ cure rate [6]. In our study, the cure rate was $83.7 \%$ in the intervention group and this was significantly better than the control group (68.6\%). Thus the WHO cure rate target is reached when patients have treatment supervised at home, whereas the control group attending a clinic for DOTS treatment lagged significantly behind. The DOT cure rate in Thailand has been reported to be $81 \%$ [9]. There was also a highly significant difference in the smear conversion rate, which was higher in intervention group patients than in the control group at all stages of treatment.

As regards compliance with treatment, reports show that compliance among TB patients is typically around $40 \%$, and that it is common for patients not to take their medication for certain periods of time $[7,8]$. Compliance, measured in terms of missed doses of medication, was $100 \%$ in our intervention group supervised by the members of the IWF. In the control group, non-compliance with treatment was recorded at different stages of treatment for different durations. The overall compliance rate in the control group was only $14.0 \%$ (12 cases out of 86).

Non-compliance in the control group was further studied to discover any factors that were associated with it. It was found that none of the demographic factors studied, including sex, family type, type of household and marital status, had a significant effect on non-compliance in the control group. High rates of non-compliance were recorded among unskilled workers and the unemployed. But the distribution of occupations in the intervention and the control groups did not differ significantly from each other so we conclude that occupation did not affect non-compliance.

Compliance in the control group was not associated in any way with the outcome of treatment as measured by sputum smear conversion rates. There was, however, a significant inverse relationship between cure rate and number of doses missed and the cut-off point was 8 doses and more. It was also found that at 6 months follow-up after treatment the defaulters and the sputum negative (cured) cases differed significantly from the sputum positive (failed treatment) cases and that positive cases recorded a significantly higher mean duration of non-compliance.

It has been stated that compliance is strongly related to the duration of chemotherapy [10]. In our study, the mean length of episodes of non-compliance were similar over the course of treatment and did not increase with increasing time of follow-up.

Our study did not measure other factors that might affect compliance, such as the time to reach the health facility, the waiting time before consultation and satisfaction with the care received. However, all control patients were referred to the nearest primary health care centre to receive their treatment and all were exposed to the same programme of care, so these are unlikely to be important factors. In Saudi Arabia, a study that aimed to define the factors that might affect compliance [11] concluded that the factors were difficult to change as they were concerned with the social characteristics of the community.

المجلة الصحية لشرق المتوسط، منظمة الصحة العالمية، المجلد التاسع، العدد ع، ب... 


\section{Conclusions}

This study confirms that treatment at home and support from trained members of an NGO would significantly improve the cure rate, smear conversion rates and the compliance rates of pulmonary TB patients, thus reducing infectivity days and preventing relapses.

\section{Acknowledgements}

This investigation received technical and financial support from the joint WHO East- ern Mediterranean Region (EMRO), Division of Communicable Diseases (DCD) and the WHO Special Programme for Research and Training in Tropical Diseases (TDR): the EMRO/DCD/TDR Small Grants Scheme for Operational Research in Tropical and Communicable Diseases.

This research work was also carried out in close collaboration with the Iraqi National Tuberculosis Programme.

\section{References}

1. March F et al. Predictors of tuberculosis transmission in prisons: an analysis using conventional and molecular methods. AIDS (London, England), 2000, 14(5):525-35.

2. Mac JT, Doordan A, Carr CA. Evaluation of the effectiveness of a directly observed therapy program with Vietnamese tuberculosis patients. Public health nursing, 1999, 16(6):426-9.

3. Weis SE et al. Treatment costs of directly observed therapy and traditional therapy for Mycobacterium tuberculosis: a comparative analysis. International journal of tuberculosis and lung disease, 1999, 3(11):976-84.

4. White AJ, Robinson-White CM, Luitel $\mathrm{H}$. A report on home visiting practices conducted in remote districts of Nepal in an NGO-run tuberculosis control programme. International journal of tuberculosis and lung disease, 1999, 3(6):534-6.

5. Zellweger JP, Coulon P. Outcome of patients treated for tuberculosis in Vaud County, Switzerland. International journal of tuberculosis and lung disease, 1998, 2(5):372-7.
6. Report on the Meeting of the National Managers of Tuberculosis Control Programmes in the Eastern Mediterranean Region, Beirut, Lebanon, 7-9 June 1999. Alexandria, WHO Regional Office for the Eastern Mediterranean, 2000:9 (WHO-EM/TUB/218/E/L).

7. Report on the third tuberculosis prevalence survey in Korea, Seoul. Seoul, Korean National Tuberculosis Association, 1975.

8. Aoki M. Comments on the results of the sixth tuberculosis prevalence survey in Taiwan area. Tokyo, Research Institute of Tuberculosis, Japan Antituberculosis Association, 1984.

9. Kamolratanakul $P$ et al. Randomized controlled trial of directly observed treatment (DOT) for patients with pulmonary tuberculosis in Thailand. Transactions of the Royal Society of Tropical Medicine and Hygiene, 1999, 93(5):552-7.

10. Murray CJL, Styblo K, Rouillon A. Tuberculosis in developing countries: burden, intervention and cost. Bulletin of the International Union against Tuberculosis, 1990, 65:6-24. 
11. Al-Hajjaj MS, Al-Khatim IM. High rate of non-compliance with anti-tuberculosis treatment despite a retrieval system: a call for implementation of directly ob- served therapy in Saudi Arabia. International journal of tuberculosis and lung disease, 2000, 4(4):345-9.

Global tuberculosis control: surveillance, planning, financing

Global tuberculosis control: surveillance, planning, financing is WHO's 8th annual report which provides an update of progress in TB control for most WHO Member States and other territories. Data presented were collected during 2003 on case notifications for 2002 and treatment results for patients registered in 2001, and compare the status of DOTS implementation within and among countries by the end of 2002. Plans for, and the major constraints to, TB control in the $22 \mathrm{HBCs}$ are also reassessed and the latest available data on expenditures (2002) and budgets (2003) are analysed. The review of the planning process includes an assessment of collaborative TB/ HIV activities in countries and the steps being taken to manage drug resistance. All the information is presented in the context of data from previous reports, allowing progress in global TB control in the past 8 years to be charted, and the prospects for reaching the targets for case detection and cure by 2005 to be considered.

The report can be obtained from Marketing and Dissemination, World Health Organization, 20 Avenue Appia, 1211 Geneva 27, Switzerland (tel: +41 22791 2476; fax: +41 22791 4857; email: bookorders@who.int). It is also available online at: http:// www.who.int/tb/publications/global_report/2004/en/contents.pdf

المجلة الصحية لشرق المتوسط، منظمة الصحة العالمية، المجلد التاسع، العدد ع، ب... 